\title{
COCAINE AND FOOD DEPRIVATION: EFFECTS ON FOOD-REINFORCED FIXED-RATIO PERFORMANCE IN PIGEONS
}

\author{
Christine E. Hughes, Raymond C. Pitts, and Marc N. Branch
}

\author{
UNIVERSITY OF FLORIDA
}

\begin{abstract}
Key pecking by 6 pigeons was maintained by a fixed-ratio 30 schedule of food presentation while body weights were $80 \%$ of free-feeding weights. Acute administration of cocaine $(0.3$ to $13.0 \mathrm{mg} /$ $\mathrm{kg}$, i.m.) dose-dependently decreased response rates. Dose-effect curves were shifted to the right when 3 of the 6 pigeons were maintained at $70 \%$ of free-feeding weights and were shifted to the left when the other 3 pigeons were maintained at $90 \%$ of free-feeding weights. Then a dose of cocaine that initially decreased response rates by more than $95 \%$ of control rates was administered before each daily session. Comparable degrees of tolerance to these rate-decreasing effects developed in the two groups. The rate at which responding recovered was relatively rapid for pigeons in the $70 \%$ free-feeding-weight group and was slower for 2 of the 3 pigeons in the $90 \%$ free-feeding-weight group. When body weights were then increased from $70 \%$ to $80 \%$ or were decreased from $90 \%$ to $80 \%$ of free-feeding weight, performance was disrupted initially only for pigeons whose weight went from $70 \%$ to $80 \%$ of free feeding. In the present experiment the degree of deprivation may have indirectly influenced the degree of tolerance that developed to cocaine's response rate-decreasing effects because it directly influenced the dose chosen to be administered chronically. The degree of deprivation appeared to have a more direct influence on the rate at which tolerance developed.

Key words: deprivation level, behavioral tolerance, cocaine, fixed-ratio schedule, key peck, pigeons
\end{abstract}

When drugs such as cocaine and $d$-amphetamine are administered repeatedly, tolerance to their behavioral effects may develop. That is, larger drug doses are required to produce the initial effect, and the dose-effect curve shifts to the right. Development of such tolerance has been shown to be a function of environmental variables such as the context in which the drug is administered (Smith,

This research was supported by Grant DA04074 from the National Institute on Drug Abuse. These data were presented in a dissertation that fulfilled part of the requirements for the $\mathrm{PhD}$ degree for the first author. Portions of these data were presented at the 17th annual convention of the Association for Behavior Analysis, Atlanta, May 1991, and at the 54th annual scientific meeting of the College on Problems of Drug Dependence, Keystone, Colorado, June 1992. Animals used in this study were cared for in accordance with guidelines of the Institutional Animal Care and Use Committee of the University of Florida and the "Guide for the Care and Use of Laboratory Animals" (Department of Health and Human Services, National Institutes of Health, Publication 85-23, revised 1985). The authors thank F. Crews, J. Farrar, B. Iwata, and E. F. Malagodi for their helpful comments on an earlier version of the manuscript, $K . F$. Schama, G. M. Sizemore, and D. J. Walker for conceptual and technical input, and, especially, J. Betts, M. Dalzin, M. Reilly, J. Steel, and T. J. Zarcone for assistance in the daily conduct of the experiment. The second author is now at the University of North Carolina at Chapel Hill.

Correspondence should be sent to the first author at the Department of Psychology, CB 3270, Davie Hall, University of North Carolina, Chapel Hill, North Carolina 27599-3270.
1990; Woolverton, Kandel, \& Schuster, 1978), the degree of stimulus control of behavior (Thompson, 1977), and a change in reinforcement frequency as a result of initial drug administration (Schuster, Dockens, \& Woods, 1966).

How reinforcers are scheduled also can determine the degree of tolerance to cocaine's rate-decreasing effects. Hoffman, Branch, and Sizemore (1987) showed that tolerance to cocaine's rate-decreasing effects developed differentially in pigeons in components of a multiple schedule arranging small fixed-ratio (FR) schedules and did not develop, or developed to a lesser degree, in components arranging larger FR schedules. Hoffman et al. suggested that strength of responding in the absence of the drug could be a determinant of the differential tolerance that developed as a function of FR size. Acute administrations of cocaine decreased response rates maintained by the small ratios to a smaller extent than responding maintained by the larger ratios. Thus, according to Nevin $(1974,1979)$, the nondrug small-ratio performance would be considered "stronger" in the sense that it was more resistant to disruption by the environmental manipulation that consisted of acute administrations of cocaine. Tolerance developed to the disruption of responding maintained by the small ratios and not to the 
disruption of responding maintained by the larger ratios. Therefore, the strength of nondrug responding was predictive of the development of tolerance.

Following from the above conceptualization, it would be profitable to examine other independent variables that (a) are conventionally viewed within the context of Nevin's (1974) resistance-to-change notion of response strength and (b) have been shown to be a determinant of acute effects of drugs. Degree of food deprivation is such a variable. For example, responding by rats maintained at a more extreme deprivation level (e.g., 20 hr without food) was more resistant to change, that is, a greater number of responses were made during extinction, than was responding maintained at a less extreme deprivation level (e.g., $5 \mathrm{hr}$ without food) (Crocetti, 1962). Therefore, behavior maintained by a higher deprivation level may be considered "stronger." It also has been shown that the acute rate-decreasing effects of a variety of drugs are attenuated as deprivation level increases; that is, dose-effect curves are shifted to the right. These drugs include cocaine (Schaal \& Branch, 1992), damphetamine (Gollub \& Mann, 1969; Samson, 1986), delta-9-tetrahydrocannabinol (Musty \& Sands, 1978), imipramine (Gundersen \& Berntzen, 1983), methadone (Kelly \& Thompson, 1988), and methamphetamine (Owen \& Campbell, 1974). Therefore, it is possible that level of deprivation may modulate the development of tolerance to the ratedecreasing effects of cocaine in the same manner as does FR size.

In the present experiment, pigeons' key pecking was maintained by an FR 30 schedule of food presentation. Acute dose-effect curves for cocaine were determined when all of the pigeons were maintained at $80 \%$ of their free-feeding weights. Body weights of half of the pigeons then were decreased to $70 \%$ of free-feeding weight, and those of the other half were increased to $90 \%$ of free-feeding weight. Dose-effect curves for cocaine were redetermined at the new weight. Schaal and Branch (1992) found systematic alterations in the response-rate-decreasing effects of cocaine when pigeons were maintained at these weights compared to the effects when pigeons were maintained at $80 \%$ of free-feeding weight. Therefore, it was predicted that the dose-effect curves for cocaine would be shifted to the right for the pigeons in the $70 \%$ of free-feeding weight group and would be shifted to the left for the pigeons in the $90 \%$ of free-feeding weight group. Then, a dose of cocaine that substantially decreased response rates was administered prior to each session. If the degree of deprivation modulates the development of tolerance in a similar manner as FR size, then tolerance should develop more rapidly, to a greater extent, or both in the pigeons in the $70 \%$ of free-feeding weight group compared to the pigeons in the $90 \%$ of free-feeding weight group.

\section{METHOD}

\section{Subjects}

Six experimentally naive adult male White Carneau pigeons (Columba livia) served as subjects. Each pigeon was housed individually in a colony room (16:8 hr light/dark) with free access to vitamin-enriched water and health grit throughout the experiment. After their arrival from Palmetto Pigeon Plant, the pigeons were given free access to food until their weights remained stable for 1 week. The mean weight over the 7 days was taken as the $100 \%$ free-feeding weight. Subsequently, weights for all pigeons were reduced to and maintained at $80 \%$ of free-feeding weight through postsession feedings of Purina ${ }^{\circledR} \mathrm{Pi}$ geon Chow and Checkers. Table 1 shows means and ranges of body weight for individual pigeons across each experimental phase.

\section{Apparatus}

Experimental sessions were conducted in an operant conditioning chamber for pigeons (Model 132-02, Lehigh Valley Electronics) with a work space measuring $35.0 \mathrm{~cm}$ deep by $30.5 \mathrm{~cm}$ wide by $35.5 \mathrm{~cm}$ high. Three response keys, $2.5 \mathrm{~cm}$ in diameter, were located in a horizontal row on the front wall, $5.6 \mathrm{~cm}$ from each other (center to center), and each side key was $8.0 \mathrm{~cm}$ from a side wall. Only the middle key was operative, and it could be transilluminated by a white light. A 1.2-W white houselight was located $5.5 \mathrm{~cm}$ above the middle response key. Pecks on the middle key with a force exceeding $0.18 \mathrm{~N}$ operated a microswitch, produced a $30-\mathrm{ms}$ tone from a Sonalert (Model Sc628) located behind the front wall $2.0 \mathrm{~cm}$ from the floor, and 
Table 1

Total number of sessions and actual presession mean body weight ( $\mathrm{g}$ ) for all pigeons across experimental phases. Numbers in parentheses are ranges of body weight.

\begin{tabular}{|c|c|c|c|c|c|c|}
\hline & \multicolumn{6}{|c|}{ Subjects } \\
\hline & \multicolumn{3}{|c|}{$70 \%$ group } & \multicolumn{3}{|c|}{$90 \%$ group } \\
\hline & 1225 & 1221 & 1457 & 7404 & 234 & 233 \\
\hline \multicolumn{7}{|l|}{ Phase 1} \\
\hline \multicolumn{7}{|c|}{$80 \%$ free-feeding weight } \\
\hline $\begin{array}{l}\text { Sessions } \\
\text { Weight }\end{array}$ & $\begin{array}{c}191 \\
433 \\
(412-455)\end{array}$ & $\begin{array}{c}134 \\
472 \\
(459-522)\end{array}$ & $\begin{array}{c}160 \\
520 \\
(492-550)\end{array}$ & $\begin{array}{c}120 \\
428 \\
(407-450)\end{array}$ & $\begin{array}{c}151 \\
523 \\
(500-539)\end{array}$ & $\begin{array}{c}192 \\
429 \\
(418-440)\end{array}$ \\
\hline \multicolumn{7}{|c|}{$70 \%$ or $90 \%$ free-feeding weight } \\
\hline $\begin{array}{l}\text { Sessions } \\
\text { Weight }\end{array}$ & $\begin{array}{c}124 \\
380 \\
(362-379)\end{array}$ & $\begin{array}{c}123 \\
411 \\
(401-425)\end{array}$ & $\begin{array}{c}155 \\
459 \\
(430-492)\end{array}$ & $\begin{array}{c}113 \\
479 \\
(459-501)\end{array}$ & $\begin{array}{c}189 \\
588 \\
(572-607)\end{array}$ & $\begin{array}{c}290 \\
481 \\
(459-497)\end{array}$ \\
\hline \multicolumn{7}{|l|}{ Phase 2} \\
\hline $\begin{array}{l}\text { Sessions } \\
\text { Weight }\end{array}$ & $\begin{array}{c}100 \\
379 \\
(364-399)\end{array}$ & $\begin{array}{c}127 \\
410 \\
(393-434)\end{array}$ & $\begin{array}{c}181 \\
448 \\
(407-488)\end{array}$ & $\begin{array}{c}179 \\
480 \\
(462-498)\end{array}$ & $\begin{array}{c}173 \\
583 \\
(560-603)\end{array}$ & $\begin{array}{c}145 \\
479 \\
(466-495)\end{array}$ \\
\hline \multicolumn{7}{|l|}{ Phase 3} \\
\hline $\begin{array}{l}\text { Sessions } \\
\text { Weight }\end{array}$ & $\begin{array}{c}169 \\
430 \\
(405-450)\end{array}$ & $\begin{array}{c}85 \\
465 \\
(450-481)\end{array}$ & $\begin{array}{c}112 \\
512 \\
(505-530)\end{array}$ & $\begin{array}{c}79 \\
429 \\
(420-440)\end{array}$ & $\begin{array}{c}77 \\
522 \\
(500-530)\end{array}$ & $\begin{array}{c}103 \\
431 \\
(420-443)\end{array}$ \\
\hline \multicolumn{7}{|l|}{ Phase 4} \\
\hline $\begin{array}{l}\text { Sessions } \\
\text { Weight }\end{array}$ & $\begin{array}{c}11 \\
427 \\
(425-430)\end{array}$ & $\begin{array}{c}17 \\
462 \\
(450-475)\end{array}$ & $\begin{array}{c}10 \\
515 \\
(507-521)\end{array}$ & $\begin{array}{c}36 \\
425 \\
(410-442)\end{array}$ & $\begin{array}{c}17 \\
525 \\
(513-534)\end{array}$ & $\begin{array}{c}10 \\
433 \\
(423-436)\end{array}$ \\
\hline
\end{tabular}

were counted as responses. An opening (5.7 $\mathrm{cm}$ by $5.2 \mathrm{~cm}$ ), through which mixed grain could be presented, was centered on the front wall, $9.0 \mathrm{~cm}$ below the middle response key. Reinforcement consisted of $4 \mathrm{~s}$ access to mixed grain. Whenever grain was presented, the houselight and keylight were turned off and the hopper was illuminated.

The chamber was located in a room with white noise continuously present. Contingencies were programmed and data were collected by a computer system (Walter \& Palya, 1984) that operated under the ECBasic control system and was interfaced with an $\mathrm{IBM}^{\circledR}$ compatible personal computer in an adjacent room. A Gerbrands Model C-3 cumulative response recorder was also used to monitor responding.

\section{Procedure}

Initial training. Following adaptation and magazine training, key pecking was shaped through differential reinforcement of successive approximations. The response requirement was increased gradually from one, across sessions, until key pecking was maintained by an FR 30 schedule. Sessions began with a 5-min timeout, during which the lights were out and the response key was inoperative, and ended after 40 food presentations or $30 \mathrm{~min}$ (not including the 5-min timeout), whichever occurred first. The first response of a session produced access to food, but was not included in calculations of response rates. The latency to the first peck, however, was recorded. Sessions were conducted 7 days a week at approximately the same time each day.

Phase 1: Acute drug effects. Drug experiments began after response rates had become stable from session to session. Performance was considered stable after 10 consecutive sessions with minimal variability and no consistent trends in response rates as determined by visual examination of daily plots of overall and run response rates (i.e., number of responses divided by the time spent responding exclusive of the postreinforcement pause). Table 1 shows the number of sessions per experimental phase for individual pigeons. Cocaine hy- 
drochloride (Sigma) was dissolved in $0.9 \%$ sodium chloride (saline) solution. Doses were determined in terms of the salt. Injections, in a volume of $1.0 \mathrm{ml} / \mathrm{kg}$ determined by the nominal $80 \%$ free-feeding weight (i.e., pigeons received the same volume every injection), were made in the left or right pectoral muscle (site alternated from injection to injection) immediately prior to selected sessions. Doses first were administered in at least two descending series that included saline, $13.0,10.0,5.6,3.0,1.0$, and $0.3 \mathrm{mg} / \mathrm{kg}$ cocaine. (Only 1 pigeon received $13.0 \mathrm{mg} / \mathrm{kg}$, and only 3 pigeons received $0.3 \mathrm{mg} / \mathrm{kg}$ cocaine.) Then, selected doses were administered one to three more times in individual pigeons. A dose of cocaine was administered only if response rates on the preceding day were within the range of response rates obtained when no drug was administered over the last 10 baseline sessions before drug experiments began (control rates). If a dose of cocaine decreased response rates outside the range of control rates, the next dose was administered at least 7 days later; if a dose did not decrease response rates outside the range of control rates, the next dose was administered at least 4 days later.

Following determination of the acute dose-effect curves for cocaine when the pigeons were at $80 \%$ of free-feeding weight, body weights were decreased to $70 \%$ of freefeeding weight in 3 pigeons by not providing postsession feedings until the new weight was reached and were increased to $90 \%$ of freefeeding weight in 3 pigeons by giving an extra $5 \mathrm{~g}$ of food postsession until the new weight was achieved. Experimental sessions continued during this weight adjustment. Which pigeons' weights were decreased or increased was determined such that each pigeon of one group was matched as closely as possible to a pigeon of the other group with respect to nondrug rates of responding. After at least 10 sessions of stable responding, the dose-effect curves were redetermined according to the procedure described above. Pigeons received the injection volume as determined by their $80 \%$ free-feeding weight. Thus, doses for each pigeon remained constant in terms of the absolute milligram of cocaine throughout the experiment.

After completion of the acute dose-effect curve for Bird 233 at $90 \%$ of free-feeding weight (Acute 1), repeated administrations of $3.0 \mathrm{mg} / \mathrm{kg}$ cocaine began (Phase 2). On the first day of Phase 2, however, $3.0 \mathrm{mg} / \mathrm{kg}$ cocaine did not suppress response rates as it had when administered acutely. The chronic regimen was suspended immediately, and after responding in the absence of the drug had stabilized, the dose-effect curve for cocaine was redetermined for this pigeon (Acute 2).

Phase 2: Chronic drug effects at $70 \%$ or $90 \%$ of free-feeding weight. After at least 10 consecutive days of stable responding following the determination of the dose-effect curves for cocaine when pigeons were at $70 \%$ or $90 \%$ of free-feeding weight, saline was administered prior to at least seven consecutive sessions. Then, a dose of cocaine that during the determination of the dose-effect curves at $70 \%$ or $90 \%$ of free-feeding weight (Acute 2 for Bird 233) suppressed response rates by at least $95 \%$ of nondrug rates was administered prior to every session. The chronic doses of cocaine for pigeons in the $70 \%$ group were $10.0 \mathrm{mg} / \mathrm{kg}$ for Birds 1225 and 1221 and 5.6 $\mathrm{mg} / \mathrm{kg}$ for Bird 1457; the chronic doses of cocaine for pigeons in the $90 \%$ group were $10.0 \mathrm{mg} / \mathrm{kg}$ for Bird 233 and $3.0 \mathrm{mg} / \mathrm{kg}$ for Birds 7404 and 234.

After at least 30 days of administration of the chronic dose of cocaine, saline was administered prior to a selected session. For 5 pigeons, the dose-effect curve for cocaine was then redetermined by occasionally substituting other doses of cocaine for the chronic dose according to the injection regimen described in Phase 1. Intervening sessions were preceded by injections of the chronic dose. For Bird 233, saline was administered prior to three separate sessions (a minimum of five intervening sessions were preceded by injections of the chronic dose) before the dose-effect curve for cocaine was redetermined. The total duration of Phase 2 ranged from 100 to 181 days (See Table 1).

Phase 3: Chronic drug effects upon return to $80 \%$ of free-feeding weight. After redetermination of the dose-effect curves for cocaine during the chronic regimen when pigeons were at $70 \%$ or $90 \%$ of free-feeding weight, body weights were increased to $80 \%$ of freefeeding weight in the pigeons in the $70 \%$ group and were decreased to $80 \%$ of freefeeding weight in the pigeons in the $90 \%$ 
group in the same manner as described in Phase 1. Pigeons received the chronic dose of cocaine prior to experimental sessions during this weight adjustment. After at least 8 consecutive days at the new weight, saline was administered prior to a session. Subsequently, for 5 pigeons, the dose-effect curve for cocaine was redetermined by substituting doses for the chronic dose according to the procedure described in Phase 2. For Bird 1225, saline was administered prior to six separate sessions, and 3.0 and $5.6 \mathrm{mg} / \mathrm{kg}$ cocaine were administered each prior to two separate sessions (a minimum of four intervening sessions were preceded by injections of the chronic dose during this assessment) before the entire dose-effect curve for cocaine was redetermined.

Phase 4: Chronic administration of saline (drug withdrawal). Following Phase 3, daily administrations of cocaine were terminated and saline was administered prior to every session for the number of sessions listed in Table 1 . Bird 7404 then was exposed to the FR schedule for an additional seven sessions without injections prior to sessions.

\section{RESULTS}

\section{Phase 1: Acute Drug Effects}

When body weights were at $80 \%$ of freefeeding weight, cocaine produced dose-dependent decreases in overall response rates for each of the pigeons (see Figure 1, open triangles; note that the $y$ axes in Figure 1 are log scales), although the smallest dose that completely suppressed response rates varied across pigeons (see Table 2 for mean response rates and ranges). Similar dose-dependent decreases were produced in run rates (response rate excluding the postreinforcement pause) and reinforcement rates; the average postreinforcement pause (PRP) and latency to the first response of the session increased as the dose increased (data not shown).

Figure 1 shows that when body weights were changed, response rates during nondrug conditions were not altered substantially for pigeons in either group. When weights were decreased from $80 \%$ to $70 \%$ of freefeeding weight, response rates for the 3 pigeons were less sensitive to the rate-decreas- ing effects of cocaine. That is, the dose-effect curves were shifted to the right. Curves for run rates were also shifted in a similar fashion for each pigeon. The diminished sensitivity to cocaine's rate-decreasing effects observed with Birds 1225 and 1221 was characterized by smaller increases in the average PRP and the latency to make the first response of the session when body weights were at $70 \%$ rather than $80 \%$ of free-feeding weight (data not shown).

Figure 1 also shows that when weights increased from $80 \%$ to $90 \%$ of free-feeding weight for 3 pigeons, overall response rates initially were slightly more sensitive to cocaine's rate-decreasing effects, and the doseeffect curves shifted to the left. For example, $3.0 \mathrm{mg} / \mathrm{kg}$ cocaine suppressed response rates by an average of $60 \%$ across the 3 pigeons when weights were $80 \%$ of free-feeding weight, but completely suppressed responding for the 3 pigeons when weights were $90 \%$ of free-feeding weight. As noted earlier, chronic administration of $3.0 \mathrm{mg} / \mathrm{kg}$ cocaine began for Bird 233, but response rates were not suppressed during the first session of the chronic regimen. Therefore, the acute doseeffect curve was redetermined (Acute 2). During Acute 2, the dose-effect curve for cocaine was shifted to the right relative to the dose-effect curve determined when Bird 233 was at $80 \%$ of free-feeding weight.

\section{Phase 2: Chronic Drug Effects at $70 \%$ or $90 \%$ of Free-Feeding Weight}

Figure 2 shows the effects of daily administration of the chronic dose for individual pigeons at the beginning of the chronic regimen averaged over two-session blocks. In general, pigeons in the $70 \%$ group started responding earlier in the chronic regimen than did pigeons in the $90 \%$ group. For example, Bird 1225's response rates increased during the first 6 days of chronic administration of $10.0 \mathrm{mg} / \mathrm{kg}$ cocaine to approximately $75 \%$ of those when saline was administered and remained at this level, on average, over the 100 days of this chronic phase. Although there was greater variability across this portion of the chronic phase for Birds 1221 and 1457, both pigeons occasionally responded at rates comparable to those seen across the rest of the phase within the first 6 days of chronic administration. After 18 sessions of the 
70\%-ffw GROUP
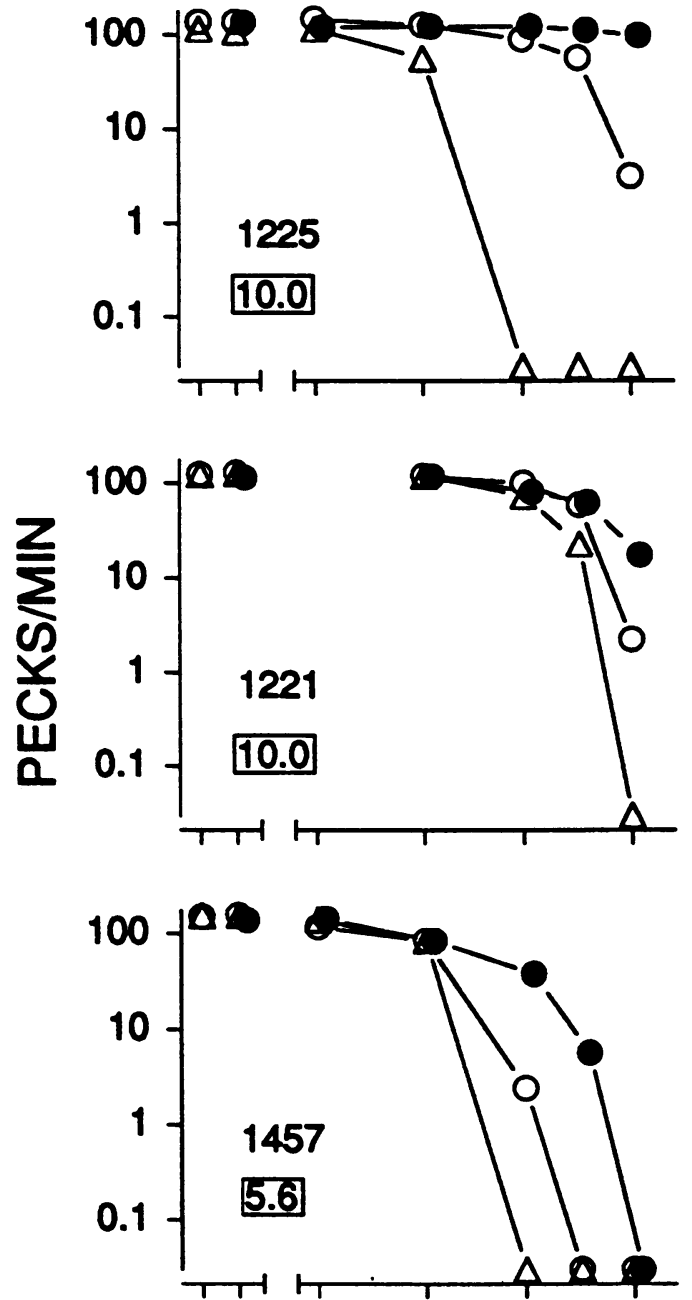

CS 0.3

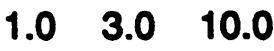

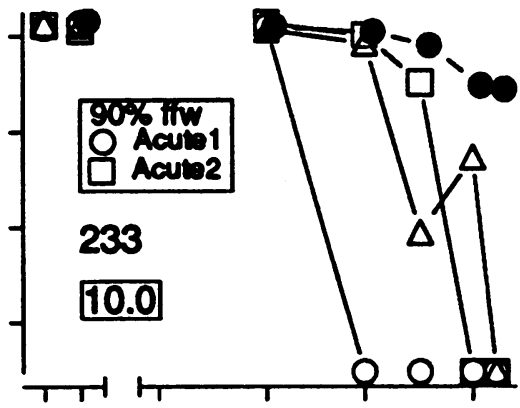

90\%-ffw GROUP
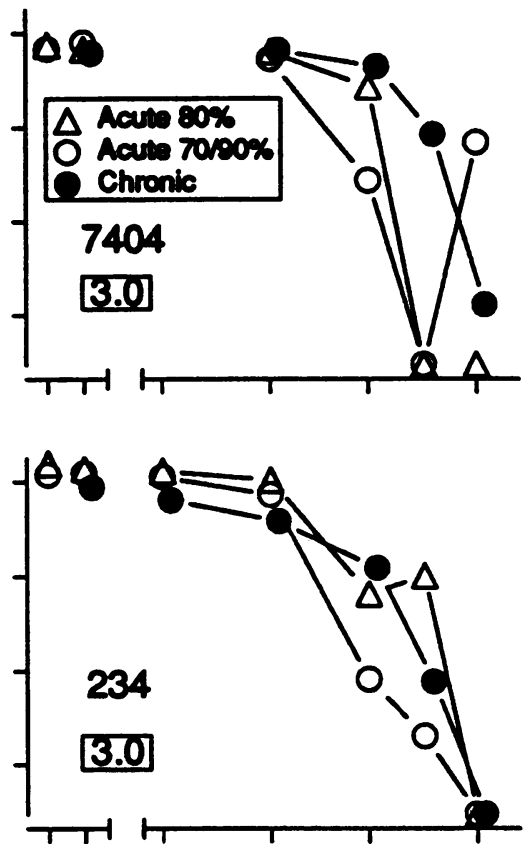

\section{COCAINE (mg/kg)}

Fig. 1. Mean overall response rates as a function of the dose of cocaine for pigeons in the $70 \%$ group (left panels) and in the $90 \%$ group (right panels) when body weights were maintained at $80 \%$ of free-feeding weight (open triangles) and $70 \%$ or $90 \%$ of free-feeding weight (open circles) during Phase 1 and were maintained at $70 \%$ or $90 \%$ of free-feeding weight during Phase 2, when cocaine was administered daily (filled circles). For Bird 233, open squares represent data from the Acute 2 determination of the effects of cocaine. Doses on $x$ axes are in terms of $80 \%$ of free-feeding weight. Points above $\mathrm{C}$ are means from sessions immediately preceding injections of a dose of cocaine or saline. The chronic dose for each pigeon is enclosed in a box below the subject number. Points above $S$ are means from sessions in which saline was administered. The rightmost points on the curves for Bird 233 are means from sessions in which $13.0 \mathrm{mg} / \mathrm{kg}$ cocaine was administered. Points above the chronic dose are means from all sessions that immediately preceded administration of saline or other doses of cocaine during the chronic regimen. All other points are means of at least two determinations. Response rates equal to zero were recorded as 0.03 responses per minute, which was the "record floor" (i.e., the rate that would have been produced by one response in the session): the inverse of the maximum session length $(30 \mathrm{~min})$. Note that filled circles are slightly displaced to the right for clarity and that both axes are logarithmic. 
chronic regimen, Bird 1221 stopped key pecking. The effects of saline and other doses of cocaine were determined. After these assessments, response rates following each administration of $10.0 \mathrm{mg} / \mathrm{kg}$ cocaine became consistent and recovered to within the range seen for the rest of the phase. The data from these initial assessments of effects are not included in the dose-effect curves in Figure 1.

In contrast to the results for the pigeons in the $70 \%$ group, response rates for 2 of the 3 pigeons in the $90 \%$ group (Birds 234 and 233) remained completely suppressed throughout the first 29 and 27 days of repeated administration of cocaine, respectively. Despite the fact that no pecking had occurred during the initial sessions of the chronic regimen, when saline was substituted for the chronic dose response rates near control levels were observed. For Bird 234, response rates after subsequent administrations of $3.0 \mathrm{mg} / \mathrm{kg}$ cocaine remained elevated at approximately $85 \%$ of response rates at the beginning of the phase when saline was administered. For Bird 233, response rates were variable until after a third saline administration; the average response rate across the next two sessions was 30.4 responses per minute and remained at about that level throughout the rest of the phase. For Bird 7404, response rates increased during the first 4 days of repeated administration of $3.0 \mathrm{mg} / \mathrm{kg}$ cocaine to approximately $50 \%$ of the rates obtained at the beginning of the phase when saline was administered. Over the rest of the phase, the range of average response rates overlapped the range of control rates (see Table 2).

After response rates had stabilized during the chronic regimen, the dose-effect curves were redetermined. Figure 1 shows that although the dose-effect curves for each pigeon shifted to the right, the degree of tolerance varied across pigeons in the two groups. The greatest degree of tolerance was evident for Birds 1225 (70\% group) and 233 (90\% group). Tolerance also was characterized by an increase in the running rate and a decrease in the PRP and latency to respond in a session relative to Phase 1 (data not shown).

\section{Phase 3: Chronic Drug Effects Upon Return to $80 \%$ of Free-Feeding Weight}

Figure 3 shows that while body weights were being increased from $70 \%$ to $80 \%$ of free-feeding weight and the chronic dose of cocaine continued to be administered prior to sessions, the 3 pigeons stopped key pecking. Response rates increased to levels comparable to those obtained in the previous phase after 8 and 10 sessions of no pecking for Birds 1221 and 1457, respectively. For Bird 1225, response rates did not increase to previous levels until 90 sessions had passed during which saline was administered prior to five separate sessions and 3.0 and $5.6 \mathrm{mg} / \mathrm{kg}$ cocaine each were administered prior to two sessions (intervening sessions were preceded by injections of the chronic dose). These data were not included in determining the doseeffect curve shown in Figure 4. As weights were decreased from $90 \%$ to $80 \%$ of freefeeding weight (right column of Figure 3) and the chronic dose of cocaine continued to be administered prior to sessions, response rates remained essentially the same for Bird 7404 and increased for Birds 234 and 233.

After weights reached $80 \%$ of free-feeding weight and response rates were stable for at least eight sessions, the dose-effect curves were redetermined. Figure 4 shows that for pigeons in the $70 \%$ group, the shape of the dose-effect curve remained the same. That is, tolerance was still evident, but the degree of tolerance was slightly lower for Bird 1225 and was slightly greater for Birds 1221 and 1457 . Tolerance was still evident for each of the pigeons in the $90 \%$ group as well, but the degree of tolerance was substantially greater for Bird 234 and slightly greater for Bird 233.

\section{Phase 4: Chronic Administration of Saline (Drug Withdrawal)}

When daily saline administration replaced daily cocaine administration, overall response rates for each pigeon returned to the range of rates observed when saline was administered acutely during Phase 1 (see Table 2). For Bird 7404, run rates did not return to levels observed when saline was administered acutely when its weight was maintained at $80 \%$ of free-feeding weight; therefore, no injection was given prior to seven sessions. Run rates remained decreased across this phase (data not shown).

\section{DISCUSSION}

Acute administrations of cocaine dose-dependently decreased response rates in 6 pi- 
Table 2

Means and ranges of overall response rates (responses per minute) for doses of cocaine for individual pigeons across experimental phases. Numbers in parentheses are the number of administrations of a particular dose.

\begin{tabular}{|c|c|c|c|c|c|c|c|c|}
\hline Subject & $\mathrm{C}^{\mathbf{a}}$ & $V^{b}$ & $0.3^{\mathrm{c}}$ & 1.0 & 3.0 & 5.6 & 10.0 & 13.0 \\
\hline \multicolumn{9}{|l|}{ Phase 1} \\
\hline \multicolumn{9}{|c|}{$80 \%$ free-feeding weight } \\
\hline 1225 & $\begin{array}{c}115 \\
97-125(15)\end{array}$ & $\begin{array}{c}107 \\
101-113(2)\end{array}$ & $\begin{array}{c}116 \\
102-130(2)\end{array}$ & \begin{tabular}{c}
\multicolumn{2}{c}{57} \\
$35-79 \quad(2)$
\end{tabular} & $\begin{array}{c}0 \\
0(2)\end{array}$ & $\begin{array}{c}0 \\
0(2)\end{array}$ & $\begin{array}{c}0 \\
0-18.3(5)\end{array}$ & 一 \\
\hline 1221 & $\begin{array}{c}124 \\
109-142(15)\end{array}$ & $\begin{array}{c}135 \\
107-138 \text { (3) }\end{array}$ & - & $\begin{array}{c}120 \\
117-124(2)\end{array}$ & $\begin{array}{c}73 \\
0-106(4)\end{array}$ & $0-85^{23}(4)$ & $\begin{array}{c}0 \\
0(2)\end{array}$ & - \\
\hline 1457 & $\begin{array}{c}156 \\
136-174(15)\end{array}$ & $\begin{array}{c}155 \\
150-158 \text { (3) }\end{array}$ & $\begin{array}{c}140 \\
138-142(2)\end{array}$ & $\begin{array}{c}102 \\
22-156(3)\end{array}$ & $\begin{array}{c}0 \\
0(3)\end{array}$ & $\begin{array}{c}0 \\
0(2)\end{array}$ & $\begin{array}{c}0 \\
0(2)\end{array}$ & 一 \\
\hline 7404 & $\begin{array}{c}74 \\
59-91 \quad(12)\end{array}$ & $\begin{array}{c}68 \\
57-78 \quad(2)\end{array}$ & - & $\begin{array}{c}63 \\
59-66 \quad(3)\end{array}$ & ${ }_{0-50}^{27}$ & $\begin{array}{c}0 \\
0(2)\end{array}$ & $\begin{array}{c}0 \\
0(2)\end{array}$ & - \\
\hline 234 & $\begin{array}{c}155 \\
134-171(17)\end{array}$ & $\begin{array}{c}137 \\
133-143(3)\end{array}$ & $\begin{array}{c}130 \\
103-164(3)\end{array}$ & $\begin{array}{c}104 \\
79-128(4)\end{array}$ & $2-11^{6}(2)$ & $\begin{array}{c}10 \\
0-30 \quad(3)\end{array}$ & $\begin{array}{c}0 \\
0(2)\end{array}$ & - \\
\hline 233 & $\begin{array}{c}134 \\
115-163(15)\end{array}$ & $\begin{array}{c}133 \\
123-143(2)\end{array}$ & - & $\begin{array}{c}117 \\
109-126(2)\end{array}$ & $\begin{array}{c}83 \\
1-140(3)\end{array}$ & $0-2 \quad 1$ & $0-22^{6}(4)$ & $\begin{array}{c}0 \\
0(2)\end{array}$ \\
\hline \multicolumn{9}{|c|}{$70 \%$ free-feeding weight } \\
\hline 1225 & $\begin{array}{c}136 \\
121-152(15)\end{array}$ & $\begin{array}{c}135 \\
131-138(2)\end{array}$ & $\begin{array}{c}145 \\
137-153(2)\end{array}$ & $\begin{array}{c}126 \\
114-138(3)\end{array}$ & $\begin{array}{c}90 \\
88-91 \quad(2)\end{array}$ & $\begin{array}{c}56 \\
1-112(3)\end{array}$ & $0-7^{3}$ & 一 \\
\hline 1221 & $\begin{array}{c}125 \\
110-134(14)\end{array}$ & $\begin{array}{c}128 \\
127-129(2)\end{array}$ & - & $\begin{array}{c}119 \\
114-124(2)\end{array}$ & $\begin{array}{c}100 \\
0-106(4)\end{array}$ & $\begin{array}{c}59 \\
0-85 \quad(4)\end{array}$ & $\begin{array}{c}2 \\
0(2)\end{array}$ & - \\
\hline 1457 & $\begin{array}{c}150 \\
127-168(18)\end{array}$ & $\begin{array}{c}156 \\
150-166(3)\end{array}$ & $\begin{array}{c}116 \\
62-158(3)\end{array}$ & $\begin{array}{c}83 \\
37-113(5)\end{array}$ & $0-7^{2}$ & $\begin{array}{c}0 \\
0(2)\end{array}$ & $\begin{array}{c}0 \\
0(2)\end{array}$ & 一 \\
\hline \multicolumn{9}{|c|}{$90 \%$ free-feeding weight } \\
\hline 7404 & $\begin{array}{c}68 \\
42-95 \quad(11)\end{array}$ & $\begin{array}{c}78 \\
72-85 \quad(2)\end{array}$ & 一 & $\begin{array}{c}53 \\
47-58 \quad(2)\end{array}$ & $0-8^{3}$ & ${ }_{0-0} \begin{array}{l}0 \\
(2)\end{array}$ & $0-14^{7}$ & - \\
\hline 243 & $\begin{array}{c}118 \\
92-140(16)\end{array}$ & $\begin{array}{c}122 \\
115-130(2)\end{array}$ & $\begin{array}{c}112 \\
103-120(2)\end{array}$ & $\begin{array}{c}72 \\
45-85\end{array}$ & ${ }_{0-1}^{1}$ (2) & $\begin{array}{ll} & 0 \\
0 & (2)\end{array}$ & $\begin{array}{c}0 \\
0(3)\end{array}$ & - \\
\hline $233^{d}$ & $\begin{array}{c}130 \\
125-148(13)\end{array}$ & $\begin{array}{c}115 \\
106-146(3)\end{array}$ & - & $\begin{array}{c}125 \\
136-140(2)\end{array}$ & $\begin{array}{c}0 \\
0(2)\end{array}$ & $\begin{array}{c}0 \\
0(2)\end{array}$ & $\begin{array}{c}0 \\
0(2)\end{array}$ & $\begin{array}{c}0 \\
0(2)\end{array}$ \\
\hline $233^{e}$ & $\begin{array}{c}137 \\
120-154(17)\end{array}$ & $\begin{array}{c}138 \\
137-139(2)\end{array}$ & - & $\begin{array}{c}138 \\
135-140(2)\end{array}$ & $\begin{array}{c}102 \\
82-123(2)\end{array}$ & $\begin{array}{c}33 \\
8-101(5)\end{array}$ & $\begin{array}{c}0 \\
0(4)\end{array}$ & $\begin{array}{c}0 \\
0(2)\end{array}$ \\
\hline
\end{tabular}

Phase 2

$70 \%$ free-feeding weight

$\begin{array}{lccccccccc}1225 & - & 135 & 119 & 122 & 123 & 112 & 98 & - \\ & & 133-138(2) & 116-123(2) & 116-128(2) & 117-128(2) & 112(2) & 78-117(10) & -18 \\ 1221 & - & 113 & - & 118 & 80 & 63 & 18 \\ & & 98-123(3) & & 116-122(3) & 31-130(2) & 0-110(4) & 0-88(12) \\ 1457 & - & 137 & 143 & 84 & 38 & 6 & 0 & - \\ & & 128-146(2) & 132-149(3) & 68-96(3) & 23-54(4) & 0-28(14) & 0(2)\end{array}$

$90 \%$ free-feeding weight

\begin{tabular}{|c|c|c|c|c|c|c|c|c|}
\hline 7404 & - & 61 & 一 & 65 & 44 & 8 & 0 & 一 \\
\hline & & $49-75 \quad(4)$ & & $54-76 \quad$ (2) & $0-63 \quad(14)$ & $0-22 \quad(5)$ & $0(3)$ & \\
\hline 234 & - & 86 & 63 & 38 & 12 & 1 & 0 & - \\
\hline & & $68-104(3)$ & $46-81$ & $6-56 \quad(4)$ & $0-53 \quad(16)$ & $0-2$ & $0(2)$ & \\
\hline 233 & - & $\begin{array}{c}142 \\
137-148(3)\end{array}$ & - & $\begin{array}{c}126 \\
117-134(2)\end{array}$ & $\begin{array}{c}110 \\
103-117(2)\end{array}$ & $\begin{array}{c}80 \\
70-90 \quad(2)\end{array}$ & $\begin{array}{c}30 \\
0-62 \quad(13)\end{array}$ & $\begin{array}{c}27 \\
0-60(4\end{array}$ \\
\hline
\end{tabular}

Phase 3

$70 \%$ free-feeding weight

\begin{tabular}{|c|c|c|c|c|c|c|c|}
\hline 1225 & - & 91 & 94 & 77 & 59 & 52 & 59 \\
\hline 1221 & - & $\begin{array}{l}-93(2) \\
136\end{array}$ & $\begin{array}{c}88-101(2) \\
-\end{array}$ & $\begin{array}{c}9-85(2) \\
146\end{array}$ & $\begin{array}{c}46-71 \\
126\end{array}$ & $\begin{array}{c}34-69(2) \\
82\end{array}$ & $\begin{array}{c}32-83(10) \\
42\end{array}$ \\
\hline & & $131-140(2)$ & & $133-160(2)$ & $107-144(2)$ & $33-118(3)$ & $0-120(9)$ \\
\hline 1457 & - & $\begin{array}{c}132 \\
119-142(3)\end{array}$ & $\begin{array}{c}144 \\
139-149(2)\end{array}$ & $\begin{array}{c}100 \\
92-108(2)\end{array}$ & $\begin{array}{c}82 \\
66-98\end{array}$ & 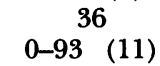 & $0-3^{2}$ (2) \\
\hline
\end{tabular}


Table 2

(Continued)

\begin{tabular}{|c|c|c|c|c|c|c|c|c|}
\hline Subject & $\mathrm{C}^{\mathrm{a}}$ & $\mathrm{V}^{\mathrm{b}}$ & $0.3^{\mathrm{c}}$ & 1.0 & 3.0 & 5.6 & 10.0 & 13.0 \\
\hline \multicolumn{9}{|c|}{ 90\% free-feeding weight } \\
\hline 7404 & - & $\begin{array}{r}56 \\
44-77 \quad(3)\end{array}$ & - & $\begin{array}{c}48 \\
45-50 \quad(2)\end{array}$ & ${ }_{12-57}^{44}(11)$ & ${ }_{1-19}^{10}(2)$ & $\begin{array}{c}0 \\
0(2)\end{array}$ & - \\
\hline 234 & - & $\begin{array}{c}116 \\
112-121(3)\end{array}$ & $\begin{array}{c}111 \\
102-120(2)\end{array}$ & $\begin{array}{r}85 \\
84-86 \quad(2)\end{array}$ & $\begin{array}{c}84 \\
73-95 \quad(11)\end{array}$ & $\begin{array}{c}74 \\
62-87 \quad(2)\end{array}$ & $0-9 \quad$ (2) & - \\
\hline 233 & - & $\begin{array}{r}154 \\
153-155(2)\end{array}$ & - & $\begin{array}{c}162 \\
151-173(2)\end{array}$ & $\begin{array}{c}126 \\
110-141(2)\end{array}$ & $\begin{array}{c}120 \\
95-144(2)\end{array}$ & $\begin{array}{c}66 \\
57-170(10)\end{array}$ & $\begin{array}{c}54 \\
47-62(2)\end{array}$ \\
\hline
\end{tabular}

a Values below C during Phase 1 are from sessions (prior to which no injections were given) immediately preceding a session in which saline or cocaine was administered.

b Values below $\mathrm{V}$ are from sessions prior to which an injection of saline was administered.

c Dashes indicate that the dose of cocaine was not administered.

d Data are from Acute 1 dose-effect curve.

- Data are from Acute 2 dose-effect curve.

geons maintained at $80 \%$ of free-feeding weight. These response-rate-decreasing effects were attenuated, that is, the dose-effect curves shifted to the right, when the body weights of 3 pigeons were maintained at $70 \%$ of free-feeding weight. The rate-decreasing effects were enhanced slightly, that is, the dose-effect curves shifted to the left, when the body weights of 3 pigeons were maintained at $90 \%$ of free-feeding weight. When cocaine was administered repeatedly while the pigeons were at their increased or decreased body weights, comparable degrees of tolerance developed to the rate-decreasing effects of a dose of cocaine that initially decreased response rates by more than $95 \%$ of control rates. Whether tolerance developed and the degree to which it developed, therefore, were not a function of the level of deprivation under the conditions of this experiment.

Manipulations of deprivation levels within the range studied in this experiment consistently produce a variety of behavioral effects across a variety of species. As deprivation level increases, (a) response rates maintained by different schedules of food presentation increase (Ferster \& Skinner, 1957; Sidman \& Stebbins, 1954); (b) the largest ratio produced under progressive-ratio schedules before the subject stops responding (i.e., the "breakpoint") increases (Hodos, 1961); (c) the amount of suppression of response rates as a function of response-produced electric shock decreases (Azrin, 1959; Azrin, Holz, \& Hake, 1963); (d) the number of errors made in a simple two-choice discrimination de- creases (Broadhurst, 1957); and (e) levels of schedule-induced polydipsia and attack increase (Dove, 1976; Falk, 1969). Therefore, the deprivation levels chosen as one of the independent variables in the current experiment are usually behaviorally significant.

It is interesting that in the present experiment overall response rates did not change appreciably when the body weights were decreased from $80 \%$ to $70 \%$ of free-feeding weight or increased from $80 \%$ to $90 \%$ of freefeeding weight. Although there was no change in overall response rates during nondrug conditions when body weights were shifted, there was a differential effect of cocaine on response rates as a function of the degree of deprivation. That is, after the degree of deprivation had been decreased, pigeons were less sensitive to the response-ratedecreasing effects of cocaine, and after the degree of deprivation had been increased, pigeons were more sensitive to these effects. Therefore, administration of cocaine revealed a functional difference of the responding maintained at the different body weights that was not evident under nondrug conditions.

The direction of the shifts in the acute dose-effect curves for cocaine as body weight was changed is consistent with the reported shifts in dose-effect curves for cocaine (Schaal \& Branch, 1992), d-amphetamine (Gollub \& Mann, 1969; Samson, 1986), delta9-tetrahydrocannabinol (Musty \& Sands, 1978), imipramine (Gundersen \& Berntzen, 1983), methadone (Kelly \& Thompson, 1988), and methamphetamine (Owen \& 

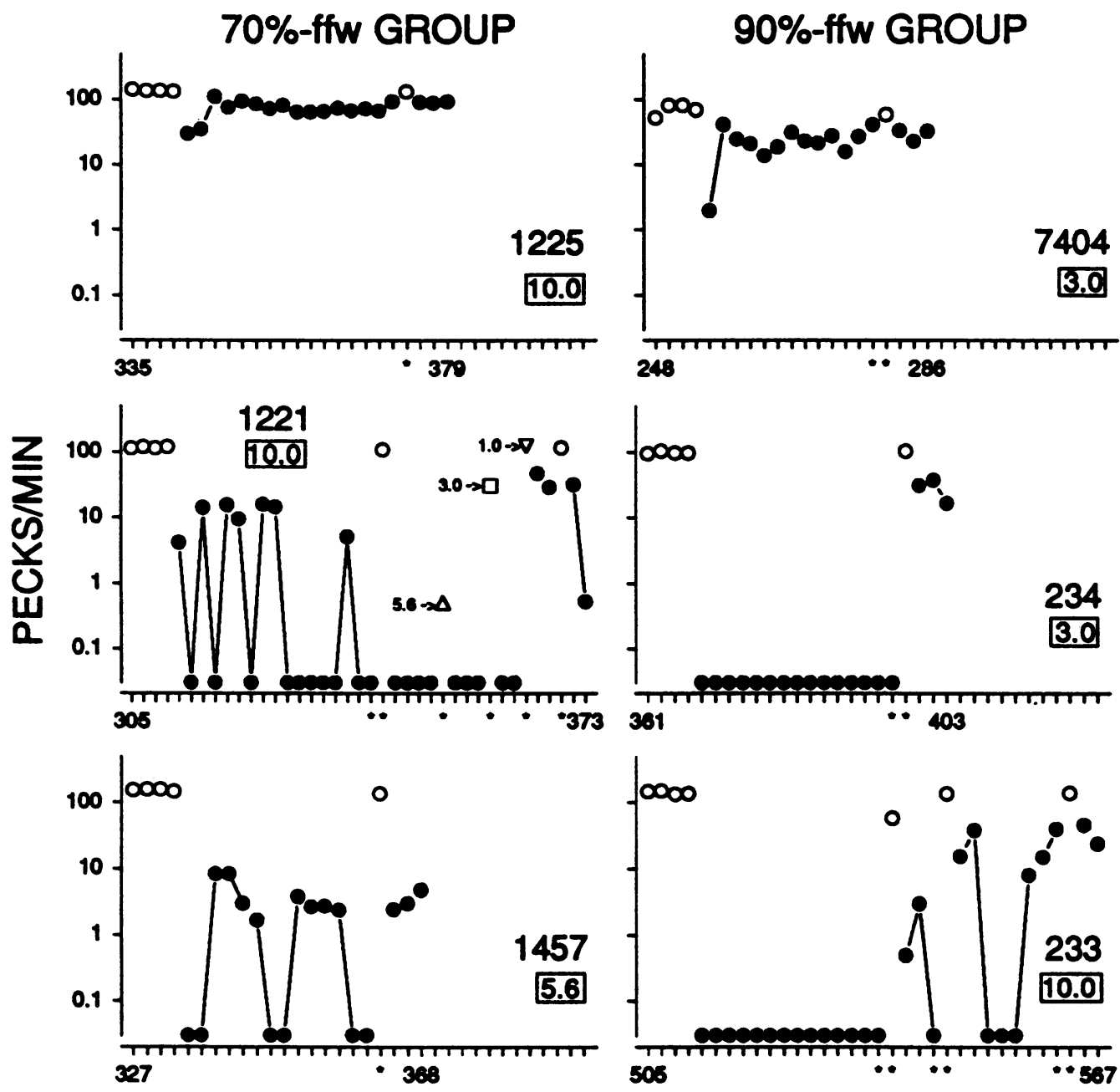

SESSIONS

Fig. 2. Mean overall response rates averaged across two-session blocks for pigeons in the $70 \%$ group (left panels) and in the $90 \%$ group (right panels) when saline (open circles) or the chronic dose (filled circles) was administered before each session. Open inverted triangles, open squares, and open triangles represent overall means from single sessions in which 1.0, 3.0, and $5.6 \mathrm{mg} / \mathrm{kg}$ cocaine were administered to Bird 1221, respectively. The chronic dose for each pigeon is enclosed in a box below the subject number. Asterisks on the $x$ axis denote one-session means.

Campbell, 1974) when the degree of food deprivation was manipulated. The direction of the shifts was also reflected in the dose of cocaine that was selected for chronic administration. Across pigeons, these doses were functionally similar. That is, for each pigeon the chronically administered dose was one that decreased response rates by at least $95 \%$ of control rates. This meant, however, that pigeons in the $70 \%$ group tended, on average, to receive a larger dose chronically than the pigeons in the $90 \%$ group. Therefore, the deprivation level directly influenced the nature of the chronic regimen. Despite differences in the magnitude of the chronic dose, however, comparable degrees of tolerance were observed in both groups of pigeons. These data contrast with studies in which the dose of the chronically administered drug influenced whether or to what degree tolerance to the response-rate, discriminative stimulus, or locomotor effects of the drug developed (Branch, 1990; Reith, 1986; Young et al., 1990). 

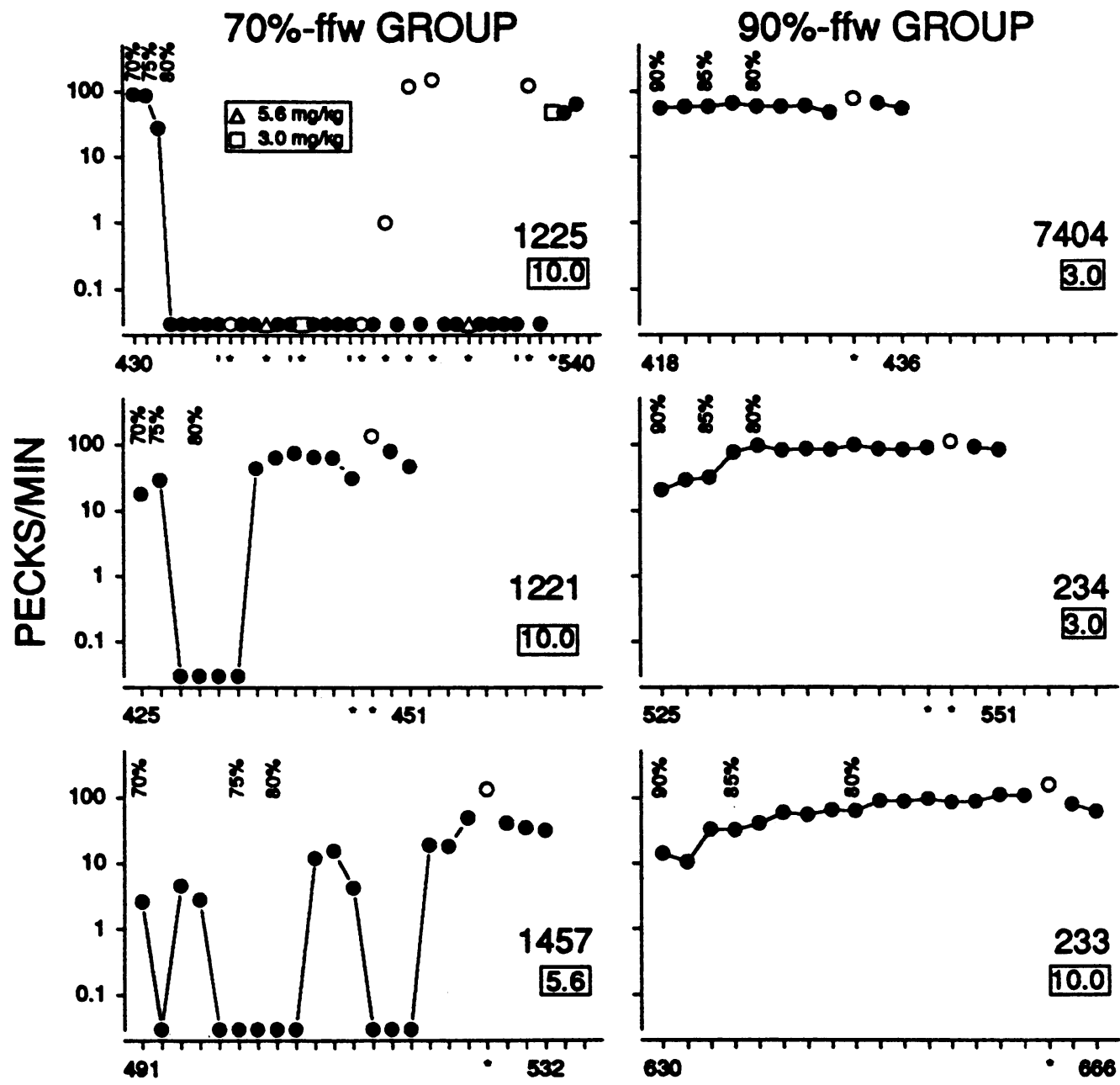

\section{SESSIONS}

Fig. 3. Mean overall response rates for pigeons in the $70 \%$ group (left panels) and in the $90 \%$ group (right panels) averaged across four-session blocks for Bird 1225 (left panel, top graph) and across two-session blocks for the rest of the pigeons when saline (open circles) and the chronic dose of cocaine (filled circles) were administered when body weights were shifted from $70 \%$ to $80 \%$ of free-feeding weight. The change in body weight is marked on the plot. Open squares and open triangles represent overall means from sessions in which 3.0 and $5.6 \mathrm{mg} / \mathrm{kg}$ cocaine were administered, respectively. Asterisks below the $x$ axis denote one-session means; vertical lines below Bird 1225's $x$ axis denote two-session means. The chronic dose for each pigeon is enclosed in a box below the subject number.

The degree of deprivation may have influenced more directly the rate of development of behavioral tolerance and how tolerance can be altered once developed. The rate at which responding recovered during repeated cocaine administration was relatively rapid for pigeons in the $70 \%$ group and relatively slow for 2 pigeons in the $90 \%$ group. In addition, during Phase 3 when body weights were shifted back to $80 \%$ of free-feeding weight in all of the pigeons (while daily drug administration continued), performance was disrupted initially for pigeons in the $70 \%$ group only (i.e., each pigeon stopped responding for a period of time). For 2 of the 3 pigeons in the $90 \%$ group (the same 2 in which tolerance was slow to develop), the rate of responding increased immediately when weights were decreased. Thus although degree of deprivation was not a determinant of 


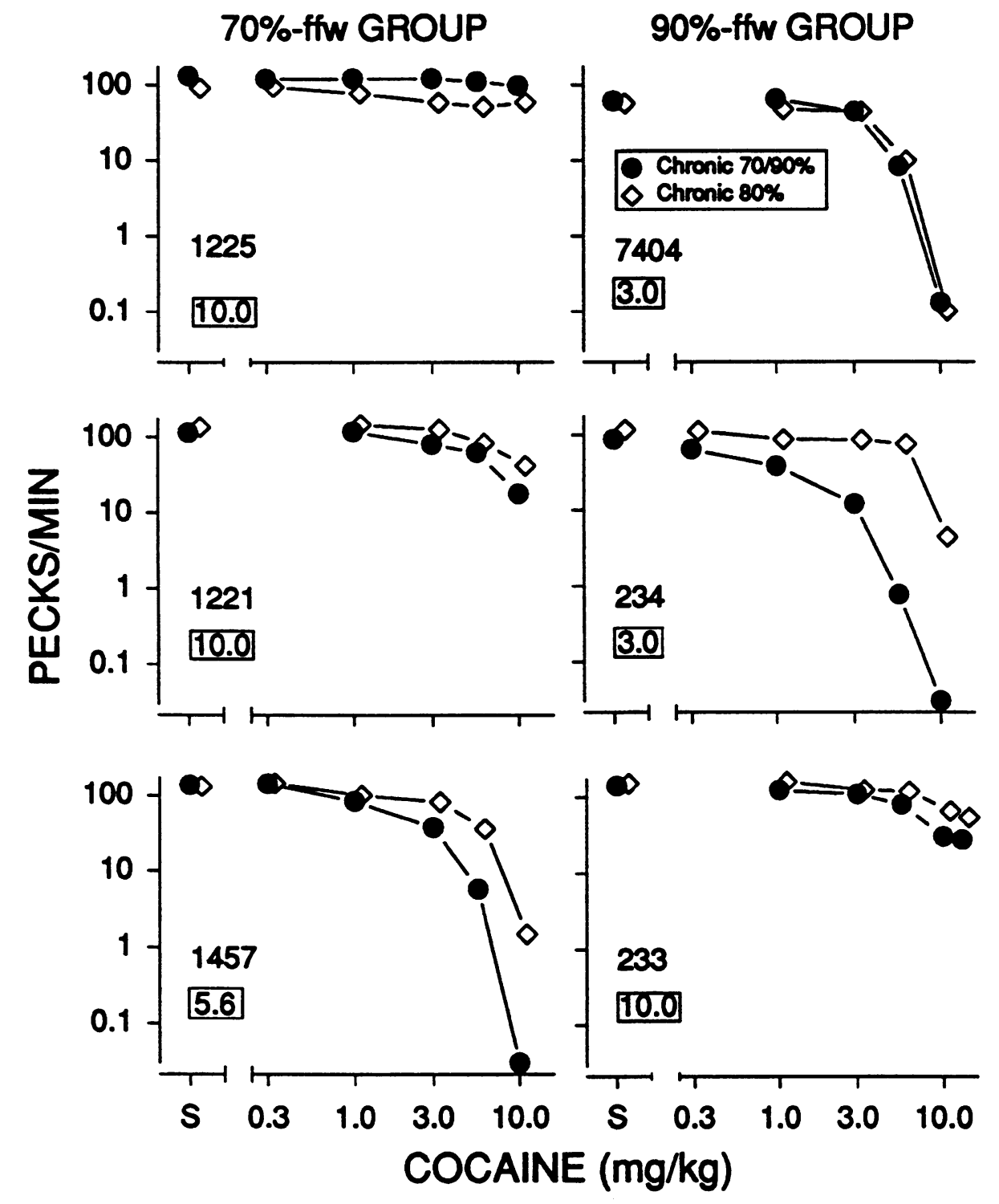

Fig. 4. Mean overall response rates as a function of the dose of cocaine for pigeons in the $70 \%$ group (left panels) and in the $90 \%$ group (right panels) when weights were maintained at $70 \%$ or $90 \%$ of free-feeding weight (filled circles) and $80 \%$ of free-feeding weight (open diamonds) when the chronic dose was administered prior to sessions. The chronic $\mathbf{7 0 \%}$ or $90 \%$ of free-feeding weight dose-effect curves are replotted from Figure 1 (filled circles). Plotting conventions are the same as Figure 1.

the degree of behavioral tolerance, it may be a determinant of when tolerance is first evident and of performance once tolerance has developed. It must be noted, however, that for Bird 7404 in the $90 \%$ group, tolerance developed rapidly, and performance was not changed when weights were decreased. Further research is necessary to determine how consistently food deprivation level modulates the rate at which behavioral tolerance develops and disrupts tolerance.

Another variable that may have contributed to the degree of tolerance observed in the present experiment was the repeated substitutions of saline and lower doses of cocaine for the chronic dose before the determina- 
tion of the dose-effect curve in Phase 2. For Birds 234 and 233 in the $90 \%$ group, response rates were suppressed completely by 3.0 and $10.0 \mathrm{mg} / \mathrm{kg}$ cocaine, respectively, until saline was substituted for the chronic dose. For Bird 1221 in the $70 \%$ group, response rates had recovered somewhat during the first 6 days of chronic administration of $\mathbf{1 0 . 0}$ $\mathrm{mg} / \mathrm{kg}$ cocaine. Subsequently, this pigeon stopped responding, and response rates recovered only after injections of saline and lower doses of cocaine. These injections resulted in a level of responding that then was maintained throughout the rest of the chronic phase. It appears that a history of being injected and responding during the experimental session during the chronic regimen may act to "induce" responding following subsequent injections of the chronic dose. Despite the apparent necessity to "induce" tolerance in these 3 pigeons, the degree of tolerance observed for 2 of the pigeons when the dose-effect curves were redetermined was comparable to that of the other pigeons.

Interestingly, during Phase 3 when its body weight was increased from $70 \%$ to $80 \%$ of free-feeding weight while the chronic dose of cocaine continued to be administered, Bird 1225 stopped responding for 90 days. The other 2 pigeons in the $70 \%$ group stopped responding for 8 to 10 days, after which their key pecking recovered. During the initial sessions of Phase 2 when the chronic cocaine regimen began, response rates for Bird 1225 were not as suppressed as response rates for Birds 1221 and 1457. That is, for the latter 2 pigeons, response rates recovered from a lower level in Phase 2 than did rates for Bird 1225. Perhaps response rates of Birds 1221 and 1457 recovered more rapidly during Phase 3 because of the history of recovered response rates during Phase 2.

During Phase 1, in which Bird 233's body weight was increased from $80 \%$ to $90 \%$ of free-feeding weight, cocaine's rate-decreasing effects were enhanced when the dose-effect curve was first determined (Acute 1), a result consistent with those of the other 2 pigeons whose weight was increased. A subsequent determination of the curve, however, revealed a shift to the right relative to the first curve (Acute 2). This portion of Phase 1 (Acute 1 and 2) lasted 290 days and included a total of 25 injections of various doses of cocaine.
It is possible that because of the substantial number of administrations of the drug over a prolonged period, the shift to the right in the dose-effect curve represents the development of tolerance to the rate-decreasing effects of cocaine. Supporting this possibility are data showing, for example, that tolerance to the response-rate-decreasing effects of $d$ amphetamine and cocaine and to the milkconsumption-decreasing effects of methylphenidate developed when the drug was administered intermittently (Emmett-Oglesby \& Taylor, 1981; Smith \& McKearney, 1977; Stafford, Branch, \& Hughes, 1994).

In summary, response-rate decreases produced by acutely administered cocaine were attenuated as degree of food deprivation was increased and accentuated as the degree of deprivation was decreased in pigeons. Therefore, it appears that the degree of deprivation was a direct determinant of the acute effects of cocaine and, therefore, the dose of cocaine that was chosen to be administered chronically. Tolerance to the rate-decreasing effects of cocaine developed for all pigeons, and the degree of tolerance did not appear to be determined by the chronic dose of cocaine. The rate at which responding recovered during repeated cocaine administration was relatively fast for all pigeons in the $70 \%$ group and relatively slow for 2 of the pigeons in the $90 \%$ group. These 2 pigeons did not start responding until after 34 (Bird 234) and 30 (Bird 233) days of repeated exposure to cocaine and administrations of saline probes. In addition, after the degree of tolerance had become stable and body weights were returned to $80 \%$ of free-feeding weight while the pigeons continued to receive the chronic dose prior to sessions, responding in the $70 \%$ group was disrupted. Nevertheless, dose-response functions were similar at both body weights once chronic administration was in effect. Thus, it appears that the level of deprivation may not be a key determinant of the degree to which tolerance develops, but may be a partial determinant of when behavioral tolerance is first evident and whether responding is disrupted during repeated administration.

\section{REFERENCES}

Azrin, N. H. (1959). Punishment and recovery during fixed-ratio performance. Journal of the Experimental Analysis of Behavior, 2, 301-305. 
Azrin, N. H., Holz, W. C., \& Hake, D. F. (1963). Fixedratio punishment. Journal of the Experimental Analysis of Behavior, 6, 141-148.

Branch, M. N. (1990). Cocaine tolerance: Interactions among random-ratio and random-interval reinforcement-schedule parameters and repeated exposure to cocaine. Drug Development Research, 20, 19-30.

Broadhurst, P. L. (1957). Emotionality and the YerkesDodson law. Journal of Experimental Psychology, 54, 345352.

Crocetti, C. P. (1962). Drive level and response strength in the bar-pressing apparatus. Psychological Reports, 10, 563-575.

Dove, L. D. (1976). Relation between level of food deprivation and rate of schedule-induced attack. Journal of the Experimental Analysis of Behavior, 25, 63-68.

Emmett-Oglesby, M. W., \& Taylor, K. E. (1981). Role of dose interval in the acquisition of tolerance to methylphenidate. Neuropharmacology, 20, 995-1002.

Falk, J. L. (1969). Conditions producing psychogenic polydipsia in animals. Annals of the New York Academy of Sciences, 157, 569-593.

Ferster, C. B., \& Skinner, B. F. (1957). Schedules of reinforcement. Englewood Cliffs, NJ: Prentice Hall.

Gollub, L. R., \& Mann, W. G., Jr. (1969). The interaction of amphetamine and body weight on a food-reinforced operant. Psychopharmacologia (Berlin), 15, 6472.

Gundersen, J. H., \& Berntzen, D. (1983). Rate dependent effects of imipramine. Scandinavian Journal of Psychology, 24, 237-242.

Hodos, W. (1961). Progressive ratio as a measure of reward strength. Science, 134, 943-944.

Hoffman, S. H., Branch, M. N., \& Sizemore, G. M. (1987). Cocaine tolerance: Acute versus chronic effects as dependent upon fixed-ratio size. Journal of the Experimental Analysis of Behavior, 47, 363-376.

Kelly, T. H., \& Thompson, T. (1988). Food deprivation and methadone effects on fixed-interval performance by pigeons. Archives Internationales de Pharmacodynamie et de Thérapie, 293, 20-36.

Musty, R. E., \& Sands, R. (1978). Effects of marijuana extract distillate and cannabidiol on variable interval performance as a function of food deprivation. Pharmacology, 16, 199-205.

Nevin, J. A. (1974). Response strength in multiple schedules. Journal of the Experimental Analysis of Behavior, 21, $389-408$.

Nevin, J. A. (1979). Reinforcement schedules and response strength. In M. D. Zeiler \& P. Harzem (Eds.), Advances in analysis of behaviour: Vol. 1. Reinforcement and the organization of behaviour (pp. 117-158). Chichester, England: Wiley.
Owen, J. E., Jr., \& Campbell, J. T. (1974). Effects of methamphetamine on fixed-ratio responding of food satiated and food deprived rats. Psychopharmacologia (Berlin), 34, 223-232.

Reith, M. E. A. (1986). Effect of repeated administration of various doses of cocaine and WIN 35,065-2 on locomotor behavior of mice. European Journal of Pharmacology, 130, 65-72.

Samson, H. H. (1986). Effect of amphetamine on sucrose-reinforced lever pressing: Interaction with food deprivation. Drug and Alcohol Dependence, 17, 323-330.

Schaal, D. W., \& Branch, M. N. (1992). Changes due to food deprivation in the effects of cocaine on the responding of pigeons. Behavioural Pharmacology, 3, 5-9.

Schuster, C. R., Dockens, W. S., \& Woods, J. H. (1966). Behavioral variables affecting the development of amphetamine tolerance. Psychopharmacologia (Berlin), 9, 170-182.

Sidman, M., \& Stebbins, W. C. (1954). Satiation effects under fixed-ratio schedules of reinforcement. Journal of Comparative and Physiological Psychology, 47, 114-116.

Smith, J. B. (1990). Situational specificity of tolerance to decreased operant responding by cocaine. Pharmacology Biochemistry and Behavior, 36, 473-477.

Smith, J. B., \& McKearney, J. W. (1977). Changes in the rate-increasing effects of $d$-amphetamine and pentobarbital by response consequences. Psychopharmacology, 53, 151-157.

Stafford, D., Branch, M. N., \& Hughes, C. E. (1994). Persistence of tolerance to effects of cocaine on schedulecontrolled behavior in pigeons. Behavioural Pharmacology, 5, 581-590.

Thompson, D. M. (1977). Development of tolerance to the disruptive effects of cocaine on repeated acquisition and performance of response sequences. Journal of Pharmacology and Experimental Therapeutics, 203, 294302.

Walter, D. E., \& Palya, W. L. (1984). An inexpensive experiment controller for stand-alone applications or distributed processing networks. Behavior Research Methods, Instruments, EO Computers, 16, 125-134.

Woolverton, W. L., Kandel, D., \& Schuster, C. R. (1978). Effects of repeated administration of cocaine on schedule-controlled behavior of rats. Pharmacology Biochemistry and Behavior, 9, 327-337.

Young, A. M., Sannerud, C. A., Steigerwald, E. S., Doty, M. D., Lipinski, W. J., \& Tetrick, L. E. (1990). Tolerance to morphine stimulus control: Role of morphine maintenance dose. Psychopharmacology, 102, 5967.

Received May 25, 1993

Final acceptance August 10, 1995 